American Journal of Applied Sciences 7 (12): 1587-1592, 2010

ISSN 1546-9239

(C) 2010 Science Publications

\title{
Validated High Performance Liquid Chromatographic Method for Analysis of Fenvalerate Pesticide in Chilies by QuEChERS Extraction Cleanup and High Liquid Chromatography
}

\author{
${ }^{1}$ Ahmed Ambarak Altorshani, ${ }^{1}$ Nor Kartini Abu Bakar and ${ }^{2}$ Eltayeb Elamin M. Eid \\ ${ }^{1}$ Department of Chemistry, Faculty of Science, University Malaya, Malaysia, \\ 50603 Kuala Lumpur, Malaysia \\ ${ }^{2}$ Laboratory of immunotherapeutic and vaccines, University Putra Malaysia, \\ Serdang 43400, Selangor DE, Malaysia
}

\begin{abstract}
Problem statement: Contamination associated with pesticide use has increased as well, adversely impacting the environment and causing human health risks through residues on food. Approach: This study reports the extraction of Fenvalerate (FE) in chilies using QuEChERS based on High Performance Liquid Chromatography (HPLC) describes a simple, fast and inexpensive method. The chillie was extracted with acetonitrile Aliquots were cleaned-up using Solid Phase Extraction (dSPE), a primary-secondary amine carbon black. Reversed-phased HPLC system with PDA detection was used for the separation identification and quantification of all these analyses using acetonitrile methanol-potassium dehydrogenate phosphate (50:40:10) as mobile phase. Results: Limit of detection of $0.01 \mu \mathrm{g} \mathrm{mL}$ was obtained. Calibration curves that constructed for the analyzes spiked into samples followed linear relationships with good correlation coefficients $\left(R^{2}>0.9944\right)$. In this method was found to be precise, specific and accurate for detection and analysis of Fenvalerate in chilies. Conclusion: QuEChERS methods are convenient, rugged methods that simplify extract cleanup, reduce material costs and improve sample throughout. Here we demonstrate the effectiveness of QuEChERS sample cleanup using a multiresidue analysis of pesticide on chilies.
\end{abstract}

Key words: QuEChERS extraction, liquid chromatography, sulphate anhydrous, synthetic pyerthroid, dehydrogenate phosphate, Solid Phase Extraction (SPE), fenvalerate pesticide

\section{INTRODUCTION}

Fenvalerate is a synthetic pyerthroid with no cyclopropane ring in the molecule: Technical-grade fenvalerate is $90-94 \%$ pure and consists of equal portions of four stereoisomer's (PR, RS, SR, SS). It may be formulated as emulsifiable concentrates, ultra-low Fig. 1.

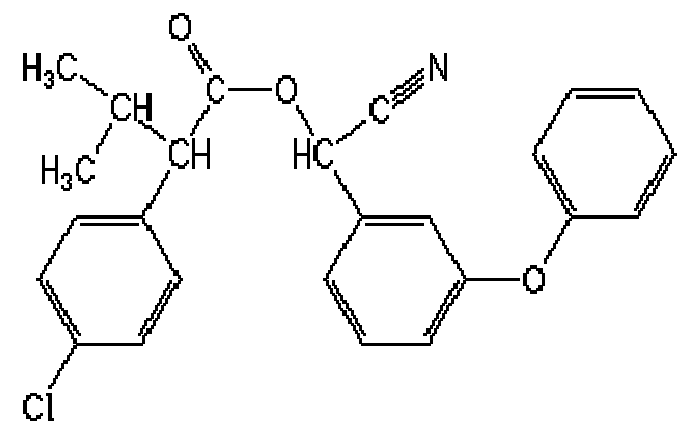

Fig. 1: Fenvalerate
Fenvalerate: Volume concentrates, dusts or wet table powder Fenvalerate formulations registered in the USA, Europe and India are emulsifiable (Royal Society of Chemistry, 1986: DuPont, 1988; MSDS, 1989; All India Medical Corp., undated). Xylene (Zuckerman, 1995) may be present in the concentrates (CPCR, 1986). fenvalerate is a highly active contact insecticide that is effective against a wide range of pests, including strains resistant to organ chlorine, organ phosphorus and carbonate insecticides. It is used mainly in agriculture, with about $90 \%$ used on cotton. It is also used on other crops, such as vines, tomatoes, potatoes, pomes, other fruit and a wide variety of other crops. SFE has been used to obtain extracts with antioxidant activity from microalgae; by using the combination of SFE and HPLC with both DAD ESIMS) (Wang et al., 2006). The extraction can be selective to some extent by controlling the density of the medium and the extracted material is easily recovered by simply depressurizing, allowing the supercritical fluid to return

Corresponding Author: Ahmed Ambarak, Department of Chemistry, Faculty of Science, University Malaya, 50603 Kuala Lumpur, Malaysia 
to gas phase and evaporate leaving no or little solvent residues. (Bravi et al., 2007). The extraction and quanantitation of pesticide residue in food matrix mostly involved liquid-liquid extraction with a great variety of solvents and a adsorbents for clean-up Analytical techniques such as Gas Chromatography (GC) and High performance are widely used to monitor the presence of these compounds in water, soils, food, fruits and vegetables. Several recent studies have reported an advance in this field. (Melo et al., 2004; Blasco et al, 2004; Oelero et al., 2003). The reported a method based on High performance liquid chromatography for determination of pesticide residues used in cauliflower (Siddiqui et al., 2009).

The supercritical fluid has approved higher diffusion coefficient and lower viscosity and surface tension than a liquid solvent, which leads to a more favorable mass transfer. Numerous methods for the determination of the residues of pyerthroid pesticides in different matrices using Solid Phase Extraction (SPE) cleanup have been developed (Jose et al., 2007). Reported good recoveries for twenty six pesticides including pyerthroid pesticides, lamda-cyhalothrin, eyfluthrin, esfenvalerate and deltamethrin in honey using Isolate ENV. (Jansson, 2000). The present communication describe isocratic High performance liquid chromatography method for simultaneous determination of ceftazidime pent hydrate and sulbactam sodium (Siddiqui et al., 2009). Densities but superior mass transfer characteristics compared to liquid solvents due to their high diffusion and very low surface tension that enables easy penetration into the porous structure of the solid matrix to release the solute (Montañés et al., 2008). (Fillion et al., 2000) described the removal of ccrextractives in fruits and vegetables using $\mathrm{C} 18$ and $\mathrm{NH} 2 \mathrm{SPE}$ cleanup, followed by GC/MS and LC fluorescence detection. Nowadays SFE method has been used to extract volatile components from various kinds of spices and plants for flavor and fragrance ingredients in pharmaceutical and food industries (Abbas et al., 2008).

\section{MATERIALS AND METHODS}

Reagents and chemicals: The pesticides have been selected on the base of their occurrence and relevance as residue in foodstuff and environmental sample as well as according to their analytical feasibility with GC and HPLC. Each analyze was provided either SigmaAldrich, Ehrenstorfer or Riedel-de Haen with the highest available purity. Single standard stock solutions were prepared dissolving $10 \mathrm{mg}$ of solid standard in 10
$\mathrm{mL}$ acetone and acetonitrile for the analyze HPLC, respectively and further diluted down to $10 \mu \mathrm{g} \cdot \mathrm{mL}^{-1}$. Multicompound standard stock solutions were prepared dissolving $10 \mathrm{mg}$ of each standard in $1000 \mathrm{~mL}$ acetone and acetonitrile for the HPLC analyze, respectively, reaching $10 \mu \mathrm{g} \cdot \mathrm{mL}^{-1}$. And further diluted to achieve concentrations of $5,2,0.5,0.2$ and $0.005 \mu \mathrm{g} . \mathrm{mL}^{-1}$. Matrix-matched standards were prepared dissolving $10 \mathrm{mg}$ of each standard in $1000 \mathrm{ml}$ blank matrix

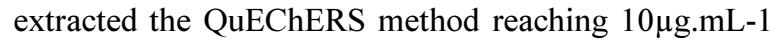
and further diluted with the matrix extracted to achieve concentrations of $10,20,30,50$ and $80 \mu \mathrm{g} . \mathrm{mL}^{-1}$. The single and Multicompound standards were stored at $4^{\circ} \mathrm{C}$ in the dark. Ultra-residue reagent acetone, ultra-residue reagent ethyl acetate, ultra-residue reagent cyclohexane, ultra-residue reagent acetonitrile, HPLC grade methanol, ultra HPLC grade water and HPLC grade formic acid were purchased from J.T. Baker. Sodium Chloride $(\mathrm{NaCl})$, sodium sulphate anhydrous $\left(\mathrm{NaSO}_{4}\right)$, magnesium sulphate anhydrous $\left(\mathrm{MgSO}_{4}\right)$, sodium chloride $(\mathrm{NaCl})$ and sodium citrate dehydrate $\left(\mathrm{C}_{6} \mathrm{H}_{5} \mathrm{Na} 307.2 \mathrm{H}_{2} \mathrm{O}\right)$ salts were purchased from J.T. Baker, di-sodium hydrogen citrate sesquihydrate $\left(\mathrm{C}_{6} \mathrm{H}_{6} \mathrm{Na} 207.1 .5 \mathrm{H}_{2} \mathrm{O}\right)$ salt was provided from Fluka and Bondesil-PSA $40 \mu \mathrm{m}$ was from Varian. The folded filters were from Whatman and the $0.45 \mu \mathrm{m}$ PTFE-membrane filters were from Sartorius. The internal standards aldrin and pant chloro nitro benzene were from Riedel-de Haen and Ehrenstorfer, respectively. The extraction and quantization of pesticide residues in food matrix mostly involved liquid-liquid extraction with a great variety of solvents and adsorbents for clean up. Analytical techniques such as Gas Chromatography (GC) and High Performance Liquid Chromatography (HPLC) are widely used to monitor the presence of these compounds in water, soils, foods, fruits and vegetables. Several recent studies have reported advances in this file (Oetero et al., 2003; Melo et al., 2004).

Preparation of calibration solutions: To prepare calibration solutions, a blank matrix containing no detectable residues of the analyzes of interest is necessary. The blank is tested as any other sample, but no ISTD is added. To compensate matrix induced effects during chromatography to a large extent, it is best to choose a matrix of the same sample type (e.g., apple for apple samples, carrots for carrot samples and so on). An aliquot of the blank extract is fortified with the desired amount of a pesticide or a pesticide mixture and a known amount of ISTD solution is added at approximately the same concentrations in the sample extracts. Pip petting ISTD solution in the very same 
way as in the sample preparation (same pipette, same volume) will help to minimize systematic errors. This means that a dilution of the ISTD is necessary. For example $1 \mathrm{~mL}$ of the blank extract is fortified with $1 / 10$ of the amount of ISTD added to the samples. To reduce matrix induced effects during GC, sample and calibration solutions should have the same concentration of co-extracted matrix components. To ensure this, some volume compensation may be necessary. In the case of MRL violations, the quantifications are performed.

\section{Sample preparation:}

Sample communication: Organically grown, pesticide-free chilies were purchased from a local grocery store. Approximately three pounds of chillie were chopped into small, bean sized cubes. Skin was included but the seeds were discarded. The chopped chilli cubes were then placed into a clean plastic bag and frozen at $20^{\circ} \mathrm{C}$ overnight. The bag was massaged occasionally to make sure the cubes remained separate. The following day, only the required amount of frozen chilli cubes was removed and thoroughly blended. Dry ice was added while comminuting, when possible. Sample were comminuted thoroughly to get the best sample homogeneity, ensuring there were no pieces of chilli visible in the final sample.

Extraction/partitioning: A $10 \mathrm{~g}( \pm 0.1 \mathrm{~g})$ amount of previously homogenized sample was placed into a $50 \mathrm{~mL}$ centrifuge tube (from the sample QuEChERS extraction). QC samples were fortified with $100 \mu \mathrm{L}$ of approximate QC spiking solution (pesticides and mixtures), respectively, yielding QC samples with concentrations of 10,50 and $80 \mu \mathrm{g} \mathrm{mL}$ of IS) was added to all samples except the control blank to yield a $100 \mu \mathrm{g} \mathrm{mL}^{-1}$ concentration in each sample. Tubes were capped and vortexed for $1 \mathrm{~min}$. A $15 \mathrm{~mL}$ amount of $1 \%$ $\mathrm{HAc}$ in CAN was added to each tube using the dispenser. An Agilent sample QuEChERS extraction salt packet from the (PN 5982-5755) containing 6g of anhydrous $\mathrm{MgSO}_{4}$ and $1.5 \mathrm{~g}$ of anhydrous $\mathrm{NaOAc}$ was added directly to the tubes. The salt bag was massaged carefully to break up any salt clumps before pouring. The tubes were examined to ensure that no powder was left in the threads or rims of the tubes. Sample tubes were sealed tightly and shaken vigorously for $1 \mathrm{~min}$ by hand to ensure that the solvent interacted with the entire sample and crystalline agglomerates were dispersed. Sample tubes centrifuged at $4000 \mathrm{rpm}$ for $5 \mathrm{~min}$.

Dispersive SPE cleanup: A $1 \mathrm{~mL}$ aliquot of the upper CAN layer was transferred to an Agilent Sample QuEChERS dispersive SPE $2 \mathrm{~mL}$ tube (p/n 5982-5058). The $2 \mathrm{~mL}$ tube contained $50 \mathrm{mg}$ of PSA carbon and 150 $\mathrm{mg}$ of anhydrous MgSO4; while the $2 \mathrm{~mL}$ tube contained $50 \mathrm{mg}$ of $\mathrm{C} 18$ and $150 \mathrm{mg}$ of anhydrous $\mathrm{MgSO}_{4}$. The tubes were tightly capped and vortexed for $1 \mathrm{~min}$ the $2 \mathrm{~mL}$ tubes were centrifuged with a microcentrifuge at 13,000 rpm for $2 \mathrm{~min}$ and $2 \mathrm{~mL}$ tubes in a standard centrifuge at $4000 \mathrm{rpm}$ for $5 \mathrm{~min}$. An aliquot from the extract, $500 \mu \mathrm{L}$ was transferred into an auto sampler vial and analyzed by HPLC.

HPLC apparatus and chromatographic conditions: HPLC system consists of Alliance separation module nodelazgas with PDA detector, the signals were processed by empower TM software (waters, Milford, MA, USA) the mobile phase composed of acetonitrile; Methanol: 0.01 potassium dehydrogenate orthophosphate (50: 40: 10). The analytical column used was C18 (symmetry 250xu.6 mm ID, $5 \mu \mathrm{m}$ particles size at an ambient temperature. The elute monitored by PDA detector at a flow rate of $1 \mathrm{~mL} \mathrm{~min}^{-1}$. in wavelength of $250 \mu \mathrm{nm}$.

Validation procedure: The validation parameters obtained were linearity/accuracy and precision. The method was validated according to WHO/FAO. The specificity was obtained by.

Linearity and Power Limit Of Quantification (LOQ): Calibration plots were constructed from blank chili spiked with FE and five concentrations (10-80 $\mu \mathrm{g}$ $\left.\mathrm{mL}^{-1}\right)$. The linearity of each calibration curve constructed by weighted $(1 / \mathrm{x})$ least-square linear regression method. The lower Limit Of Quantification (LOQ) is the lowest concentration of the analyze that can be determined with acceptable precision and accuracy.

Precision and accuracy: The intra-day and inter-day precision and accuracy of the method were determined by percent Coefficient of Variation ( $\% \mathrm{CV})$ and Percentage relative Error $(\% \mathrm{PE})$ respectively, according to the percentage WHO/FAO. Quality Control (QC) samples containing 20,50,70 $\mathrm{g} \mathrm{mL}$ concentrations accuracy. Three replicates at each concentration were processed as described in the sample preparation on day $1,2,3$ and 15 to determine intra-day and inter-day precision and accuracy. The \%PE values were calculated by the following equation:

$(\mathrm{C} \mathrm{C}-\mathrm{C}) / \mathrm{AC}) \times 100$

Where:

$\mathrm{CC}=$ Calculated concentration

$\mathrm{AC}=$ Add concentration 
Recovery: The recovery of FE was determined to QC samples at three samples pools $20,50,70 \mu \mathrm{g} \mathrm{mL}$ three replicates of each QC Sample were treated mentioned in the sample preparation previously and injected into HPLC system. The extraction recovery was calculated by following equation recovery-(peak area after extraction $) /($ Peak area direct injection $) \times 100$.

\section{RESULTS}

Using method QuEChERS, the entire procedure is faster, easier, offers time and lab our savings, while ensuring consistency. Analysts can process-10-30 samples in just a few hours (Fig. 2). The retention times were $5.4 \mathrm{~g}$ and $7.33 \mathrm{~min}$ for chili and fenvalerate respectively, with a total un time of less than $10 \mathrm{~min}$. The analytical process of fenvalerate and chili were resolved with good symmetry. No interfering peaks were observed in individual blank chili at the retention time of fenvalerate and chili, thus confirming the specificity of the method. System suitability parameters for the method were as follows: theoretical plates of fenvalerate and chili were 8530 and 4608 respectively.

The peak area ratio of FE to chillie was for the quantification of F.E in chillie samples Fig. 3, the mean of five calibration curve was linear in the set of extraction. The mean calibration range of $10-80 \mu \mathrm{g} \mathrm{mL}$ and equation of the five points was points $\mathrm{y}=0.0508$ 0.074 with correlation coefficient(r) of 0.9944 .

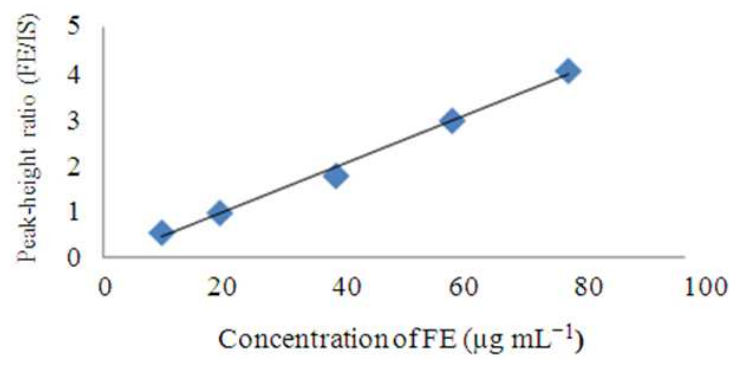

Fig. 2: Calibration curve of fenvalerate obtained with chromatograms of different concentration

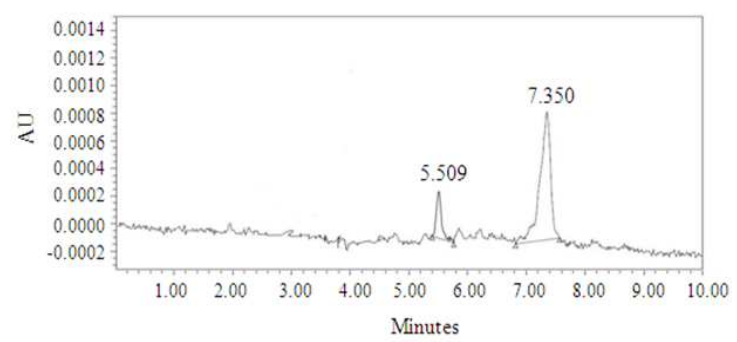

Fig. 3: Spiked sample chillie

Figure 3 shows the mean of calibration curves made over a period of 14 days, each calibration curve originating from a new set of extraction. The mean calibration curve was linear in the concentration range of $10-80 \mu \mathrm{g} \mathrm{mL}$ and equation of the five point was $\mathrm{y}=$ $0.0508 x-0.075$ with correlation coefficient(r) of 0.9944 . the accuracy and precision were evaluated with QC samples and precision were shown in Table 1 at concentration of $20,50,70 \mu \mathrm{g} \mathrm{mL}$.

\section{DISCUSSION}

The intra-day precision expressed as percentage error was determined by the analysis of three replicates of QC sample at three different concentrations. The inter-day accuracy and precision were determined on three different days and the results were shown in Table 1. The inter-day and intra-day of the QC values were satisfactory with C.V \% less than and accuracy with $\mathrm{RE}$ within $\pm 0.2 \%$.

The lower LOQ was calculated by determining the concentration of four spiked calibration stands and was found to be $10 \mu \mathrm{g} \mathrm{mL}$ for F.E in chillie with C.V less $20 \%$ and the accuracy of $81-112 \%$. The Limit Of Detection (LOD) was determined to be 0.01 $\mu \mathrm{g} \mathrm{mL}$ based on single to noise ratio $(\mathrm{s} / \mathrm{n})$ ratio of $3: 1$. The extraction recovery was determined by standard addition at three different concentrations 20, 50, $70 \mu \mathrm{g} \mathrm{mL}$ For fenvalerate and one concentration $10 \mu \mathrm{g} \mathrm{m}^{-1}$ for chillie and was found to be $90 \pm 03,84 \pm 2$ and $82 \pm 7$ for fenvalerate and $95 \pm 3$ for chillie Table 2. Determination of sample. The method described above was carried out to determine the residue of fenvalerate in chillie leaf sample. The chromatogram of the blank chillie leaf sample and the chillie leaf sample are shown in Fig. 4 and 5 respectively.

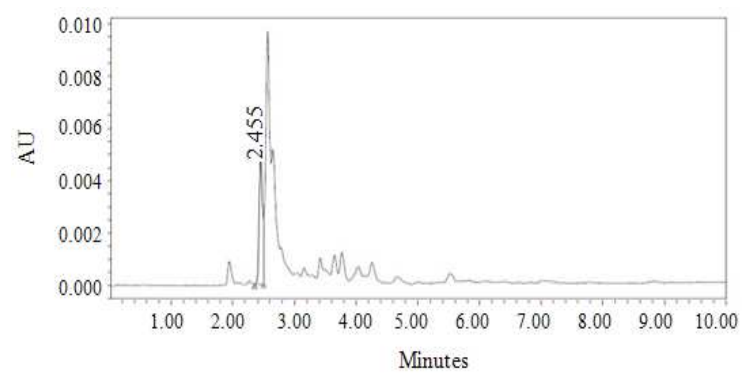


Fig. 4: Chromatogram of the blank chillie leaf sample

Table 1: Intra-day and inter-day coefficient of variation and relative error

\begin{tabular}{|c|c|c|c|c|c|c|}
\hline \multirow[b]{2}{*}{ Nominal conc. $\left(\mu \mathrm{g} \mathrm{mL}^{-1}\right)$} & \multicolumn{2}{|c|}{ Calculated conc. $\left(\mu \mathrm{g} \mathrm{mL}^{-1}\right)$} & \multicolumn{2}{|l|}{ C.V\% } & \multicolumn{2}{|l|}{$\% \mathrm{RE}$} \\
\hline & Intra-day & inter-day & intra-day & inter-day & intra-day & inter-day \\
\hline 20 & $18.4 \pm 0.4$ & $18 \pm 0.3$ & 2.1 & 1.7 & 8.03914 & -0.10 \\
\hline 50 & $41.2 \pm 3.2$ & $42.6 \pm 1.6$ & 7.8 & 3.7 & 17.5822 & -0.15 \\
\hline 70 & $65.8 \pm 3.9$ & $66.9 \pm 1.3$ & 5.9 & 2.0 & 6.01201 & -0.04 \\
\hline
\end{tabular}

Table 2: Fenvalerate recovery and accuracy of the assay

\begin{tabular}{|c|c|c|c|c|c|}
\hline \multirow[b]{2}{*}{ Conc. $\left(\mu \mathrm{g} \mathrm{mL}^{-1}\right)$} & \multicolumn{3}{|l|}{ Absolute recovery } & \multicolumn{2}{|l|}{ Accuracy (\%) } \\
\hline & Conc. $\left(\mu \mathrm{g} \mathrm{mL}^{-1}\right)$ mean $\pm \mathrm{SD}$ & Mean $(\%) \pm \operatorname{SD~} n=3$ & C.V\% & Mean $\pm \operatorname{SD} n=3$ & C.V\% \\
\hline 20 & $1.84 \pm 0.4$ & $90 \pm 0.3$ & 0.3 & $91 \pm 2$ & 2 \\
\hline 50 & $4.12 \pm 3.2$ & $84 \pm 1.6$ & 2 & $82 \pm 7.8$ & 8 \\
\hline 70 & $6.58 \pm 3.9$ & $95 \pm 1.3$ & 1 & $93 \pm 5$ & 5 \\
\hline
\end{tabular}

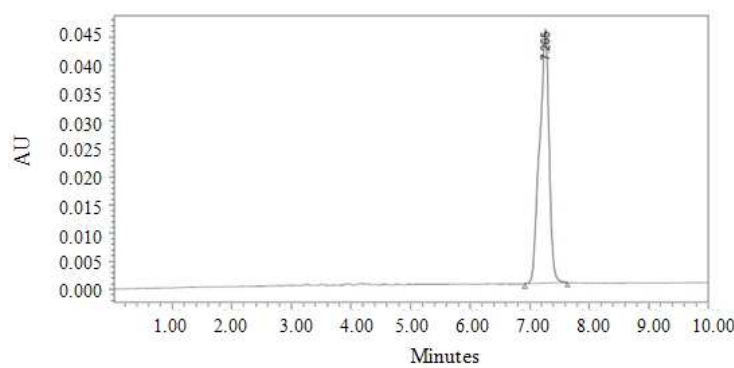

Fig. 5: Chromatogram of fenvalerate standard solution

\section{CONCLUSION}

The newly developed HPLC method for determination of Fenvalerate in Chillie was found to be simple, accurate, specific and robust. No interference peaks were observed at the retention time of both fenvalerate and pant chlorobenzene. The proposed method was successfully applied to analyze Chillie sample by using the QuEChERS extraction. Therefore, this method is suitable for monitoring Fenvalerate residue in Chillie, compared with other separation techniques. It is a more rapid, simple and effective method for determination of pyerthroid residues.

\section{REFERNCES}

Abbas, K.A., A. Mohamed, A.S. Abdulamir and H.A. Abas, 2008. A review on supercritical fluid extraction as newanalyticalmethod. Am. J. Biochem. Biotechnol., 4: 345-353. DOI:10.3844/ajbbsp.2008.345.353

Blasco, C., G. Font and Y. Pico, 2004. Determination of dithiocarbamates and metabolites in plants by liquid chromatography-mass spectrometry. J.
Chromatogr. A., 1028: 267-276. DOI: 10.1016/J.CHROMA.2003.12.002

Bravi, E., G. Pperretti, L. Motanari, F. Favati and P. Fantozzi, 2007. Supercritical fluid extraction for quality control in beer industry. J. Supercrit. Fluids, 42: 342-346. DOI: 10.1016/j.supflu.2007.02.012

MSDS, 1989. MSDS Reference for Crop Protection Chemicals. 2nd Edn., Chemical and Pharmaceutical Press, New York, pp: 1492. ISBN: 0471510289

CPCR, 1986. Crop Protection Chemicals Reference. 2nd Edn., Chemical and Pharmaceutical Press, New York, pp: 2030. ISBN: 0471848247

DuPont, 1988. Material safety data sheet. DuPont Corporate.

Fillion, J., F. Sauke and J. Selwyn, 2000. Multiresidue method for the determination of residues of 251 pesticides in fruits and vegetables by gas chromatography/mass spectrometry and liquid chromatography with fluorescence detection. J. AOAC Int. 83: 698-713. PMID: 10868594

Zuckerman, A.J., 1995. IARC monographs on the evaluation of carcinogenic risks to humans. J Clin. Pathol., 48: 691-691. PMCID: PMC502736 DOI:10.1136/jcp.48.7.691-a

Jansson, C. 2000. Multiresidue method for the gas chromatographic determination of pesticides in honey after solid-phase extraction cleanup. J. AOAC Int., 83: 714-719. PMID: 10868595

Jose, A.M., H. Miguel, C. Alejandro and I. Elena, 2007. Use of compressed fluids for sample preparation. Food Applied J. Chromatog. 1152: 234-246. DOI: 10.1016/j.chroma.2007.02.046

Melo, L.F.C., C.H. Collins and I.C.S.F. Jardim, 2004. New materials for solid-phase extraction and multiclass high-performance liquid 
chromatographic analysis of pesticides in grapes. J. Chromatogr. A., 1032: 51-58. DOI: 10.1016/J.CHROMA.2003.10.101

Montañés, F., N. Corzo, A. Olano, G. Reglero and E. Ibáñez et al., 2008 Selective fractionation of carbohydrate complex mixtures by supercritical extraction with $\mathrm{CO} 2$ and different co-solvents . J. Supercrit. Fluids, 45: 189-194. DOI:10.1016/J.SUPFLU.2007.08.012

Oetero, R.R., B.C. Grande and J.S. Gándara, 2003. Multiresidue method for fourteen fungicides in white grapes by liquid-liquid and solid-phase extraction followed by liquid chromatographydiode array detection. J. Chromatogr. A., 992: 121131. DOI: 10.1016/S0021-9673(03)00317-0

Siddiqui, M.R., A. Tariq, M. Chaudhary, K.D. Reddy and P.S. Negi et al., 2009. Development and validation of high performance liquid chromatographic method for the simultaneous determination of ceftazidime and sulbactam in spiked plasma and combined dosage formzydotam. Am. J. Applied Sci., 6: 1781-1787. DOI:10.3844/ajassp.2009.1781.1787

Wang,Y., W. Yiping, J. Yang, R. Pfeffer and R. Dave et al., 2006. The application of a supercritical antisolvent process for sustained drug delivery. J. Powder Technol., 164: 94-102. DOI: 10.1016/j.powtec.2006.03.004 